\title{
Influence of Simmering and Frying on Tetracycline Residues Detected in Broiler Chicken Meat
}

\author{
Heba Mohamed Shaheen ${ }^{1}$, Ali Meawad Ahmed ${ }^{1 *}$, Hosny Abdelltief Abdelrahman ${ }^{1}$, Rania \\ Helmy Авонаtab Abdou ${ }^{2}$, Aya Salama Mohamed Kamel ${ }^{1}$
}

${ }^{1}$ Department of Food Hygiene, Faculty of Veterinary Medicine, Suez Canal University, Egypt; ${ }^{2}$ Department of Forensic Medicine and Toxicology, Faculty of Veterinary Medicine, Suez Canal University, Egypt.

\begin{abstract}
Antibiotic resistance is growing to dangerously high levels in all foods of the sector. Tetracyclines are the most conventionally used antibiotics for raising chicken in Egypt. The occurrence of antibiotic residues in broiler chicken is the chief causes of the development of antibiotic resistance in food-borne pathogens. Antibiotic resistance is setting the achievements of present day medication at chance. Therefore, in this study 300 chilled broilers carcasses were collected from different poultry markets in Ismailia City, Egypt to evaluate qualitative, quantitative and tetracycline levels. Qualitative determination of tetracycline residues was done using rapid tetracycline test kit. Second aim of the study was fined a safe way to control the hazards of tetracycline concentrations through study the influence of simmering and frying on these residues. Quantitative determination of tetracycline residues was done using High Performance Liquid Chromatography. The results revealed that the incidence of tetracycline residues was 260 (87\%) in all examined chicken meat. The average concentration values of oxytetracycline (OTC), tetracycline (TTC), chlorotetracycline (CTC), and doxycycline (DOC) in broiler samples were $160.26,89.19,98.75$, and $175.64 \mu \mathrm{g} / \mathrm{Kg}$ respectively. Based on the local and international regulations, the results revealed that out of 260 positive samples for tetracycline levels, 170 (65.4\%) were unfit the maximum residual limit and 90 (34.6\%) broiler samples were agreed with the MRL. After the samples were simmered, the average concentration values of OTC, TTC, CTC, and DOC were significantly reduced $(\mathrm{P}>0.05)$ to $18.71,8.70,10.45$, and $23.15 \mu \mathrm{g} / \mathrm{Kg}$ respectively, with reduction parentage of $87 \%, 89 \%, 88 \%$ and $86 \%$ respectively. The results of the study emphasis that TCS resides still problems in the broilers meat traded at Ismailia City, Egypt. Cooking by simmering is the best method guarantee consumers almost safe of broiler chicken meat.
\end{abstract}

Keywords | Tetracycline, Resides, Chicken, Consumers, Cooking

Received | January 02, 2022; Accepted | January 27, 2022; Published | March 03, 2022

*Correspondence | Ali Meawad Ahmed, Department of Food Hygiene, Faculty of Veterinary Medicine, Suez Canal University, Egypt; Email: ameawad@yahoo. com

Citation Shaheen HM, Ahmed AM, Abdelrahman HA, Abdou RHA, Kamel ASM (2022). Influence of simmering and frying on tetracycline residues detected in broiler chicken meat. Adv. Anim. Vet. Sci. 10(4): 725-730.

DOI | https://dx.doi.org/10.17582/journal.aavs/2022/10.4.725.730

ISSN (Online) | 2307-8316

\section{INTRODUCTION}

$\mathrm{C}^{2}$ hicken meat is a precious source of protein, minerals, and other nutrients that is why it is widely established as the main important food in Egypt. Hence, the Egyptian government had supported broiler farming and their industry to withstand protein sufficiency. Yearly, chicken consumption is about 1.2 billion broilers in Egypt, which is equivalent to broiler meat of 1125 million tons (Henry et al., 2019). In addition, the total consumption of broilers in Egypt is probable to increase from 993,000 tons in 2017 to $1,156,000$ tons in 2026 (FAO, 2017). High mortality rates in chicken farms challenged the farmers to use feed supplemented which acts as prophylactic agents, growth promotors, and immune stimulants. Nowadays, the recent integrated and intensified chicken production demands antibiotics to control infectious diseases, enhance growth endorsement, and meet the demands of an ever-expanding world population.

Veterinarians started using antibiotics to manage chicken disease in 1950 as animal food additives (Sivagami et al., 2018). However, abusing antibiotic doses without following obligatory withdrawal periods leads to accumulation of 
their concentration in the meat and finally turns into part of the consumers' food chain. Antibiotics may remain in the broiler's meat leading to potential human health hazards toxicologically, microbiologically, or immunopathologically (Gowtham et al., 2020). Tetracyclines are recommended for use in an extensive variety of farm animals, including poultry (Nguyen et al., 2013). Tetracyclines are a broad-spectrum bacteriostatic agent that inhibits protein synthesis by preventing attachment of aminoacyl RNA to the ribosomal acceptor (A) site (Rusu and Buta, 2021). Tetracyclines have an ordinary four-ring structure to which different side chains are attached (Tariq et al.,2018). Tetracyclines (TCS), including oxytetracycline (OTC), tetracycline (TTC), chlortetracycline (CTC), and doxycycline (DOC), are considered the main antibiotics used in chicken farms. Tetracycline compounds are approved by both European Union and the USA, Food and Drug Administration for therapeutic, nutritional, and prophylactic use in chicken (Nikolaidou et al., 2008). The withdrawal periods of tetracycline ranged between 5 to 15 days when used in chicken production (Mund et al., 2017; Kulandaivelu et al., 2018). The abuse using or insufficient withdrawal period of tetracycline may develop to drug residues in the chicken meat. Tetracycline may have health risks such as transfer of antibiotic-resistant bacteria to the consumers, immunopathological effects, autoimmunity, carcinogenicity, mutagenicity, nephropathy, hepatotoxicity, reproductive disorders, bone marrow toxicity, or allergy (Nisha, 2008).

To prevail over the antibiotic residues in broilers, currently lots of investigations going on using safe methods for consumers. Regular cooking methods can play a considerable role in reducing tetracycline residue (Javadi, 2011; Abou-Raya et al., 2013; Hussein et al., 2016; Gowtham et al., 2020). Trustworthy data on the chicken drugs in general and of tetracycline in particular, are not easy, especially in Egypt. Periodical determination of tetracycline residues in broilers meat is an issue that needs to be further investigated. Therefore, this paper is firstly searching the incidence of tetracycline residues in chicken at Ismailia markets-Egypt using rapid tetracycline test kits. Second aim was studied the influence of simmering and frying on tetracycline residues using High Performance Liquid Chromatography.

\section{MATERIALS AND METHODS}

\section{Samples Collection}

A total of 300 broilers carcasses were collected from various poultry markets at Ismailia City, Egypt. The chilled broiler was weighted from 900 to $1150 \mathrm{~g}$. Each carcass was individually placed in sterile coolers and directly transferred into Food Hygiene Laboratory at the Faculty of Veterinary Medicine in Suez Canal University, Egypt for further evaluation. All samples were evaluated for tetracycline residues qualitatively by Rapid Tetracycline Test kit and quantitatively by High Performance Liquid Chromatography (HPLC). Broilers meat samples containing high levels of tetracycline (above $100 \mu \mathrm{g} / \mathrm{Kg}$ ) were selected to study the effect of simmering and frying methods on their concentration levels.

\section{QUALITATIVE DETERMINATION OF TETRACYCLINE} RESIDUES

Rapid Tetracycline Test kit (Quicking Biotech Co., Ltd. Shanghai, China) was used for evaluation of the broiler samples for the incidence of tetracycline in their tissues above $25 \mu \mathrm{g} / \mathrm{Kg}$ (Tetracycline Rapid Test Kit, 2010). Each carcass was deboned and minced their meat then, mixing thoroughly. Four grams from former minced sample with $0.5 \mathrm{~mL}$ of assay buffer in the tubes were homogenized at $10,000 \mathrm{rpm}$ for $1 \mathrm{~min}$. The tubes were put into the water bath at $80^{\circ} \mathrm{C}$ for $10 \mathrm{~min}$, then the extract was harvested into $1.5 \mathrm{~mL}$ centrifugal tubes. Further centrifugation was carried out at $4000 \mathrm{rpm}$ for $1 \mathrm{~min}$ to make the extract more clear. About $0.2 \mathrm{ml}$ of the extract was pipetted into a microwell. The samples were continually extruded until all red reagents were completely dissolved. Gradually three drops of extract were dripped into the sample well "S" of the Cassette horizontally. The results were interpreted within 5-10 min. The results after $10 \mathrm{~min}$ were only measured as a reference.

\section{CONTROL OF TETRACYCLINE RESIDUES}

From the positive broiler samples for TCS residues, 10 samples were used in simmering and frying cooking. The broiler carcasses were simmered by placing it in boiling water for 20 minutes then kept just below $84^{\circ} \mathrm{C}$ until cooked ( $1 \mathrm{~h} \pm 10 \mathrm{~min}$.). The cooked meat had a well-done appearance on the outside. Chicken slices were fried for 15 minutes using sunflower oil (food grade) in a pan at $180^{\circ} \mathrm{C}$, turning occasionally. The cooked meat had a well-done appearance on the outside. After both cooking treatments, all samples were ground, weighed $(2 \pm 0.05 \mathrm{~g})$, and placed in a $50 \mathrm{ml}$ polypropylene centrifuge tube for HPLC analysis.

\section{QUANTITATIVE DETERMINATION OF TETRACYCLINE RESIDUES}

The determination of tetracycline residues by HighPerformance Liquid Chromatography was the following Şenyuva et al. (2000). An Agilent 1100 HPLC system (Germany) consisting of a quaternary pump G1321A, a vacuum degasser G1222A, an automatic injector G1329A with sample tray G1230A, a column thermostat G1216A, a fluorescence detector G1221A, a multiple wave detector $\mathrm{G} 1365 \mathrm{~B}$, and integration software (ChemStation G2170AA and G2180AA) was used. Analytical column 
type Agilent C18; $5 \mu \mathrm{m}, 250$ x $4.6 \mathrm{~mm}$ (catalogue no. 1111-3500).

\section{Extraction}

Two grams of the minced samples were put in $50 \mathrm{~mL}$ polypropylene centrifuge tubes and homogenized in a blender for 2 minutes and then $0.1 \mathrm{~mL}$ citric acid was added. One $\mathrm{mL}$ nitric acid 30\%, $4 \mathrm{ml}$ methanol, and $1 \mathrm{~mL}$ deionized water was added, respectively. The suspension with firm particles was transferred into a vortex (Stuart/ UK) for mixing then kept in an ultrasonic bath (BranSonic/ USA) for 15 minutes and centrifuged (Sartorius/ Germany) for 10 minutes at $5300 \mathrm{rpm}$. After filtering through a 0.45 $\mu \mathrm{m}$ nylon filter, $25 \mu \mathrm{L}$ of the solution was injected into HPLC for analysis.

\section{Chromatographic conditions}

Isocratic separation was achieved using an Agilent C18 $(5 \mathrm{~mm} 250 \times 4.6 \mathrm{~mm})$. The mobile phase consisting of distilled water $\left(\mathrm{pH}=2.2\right.$ with $\left.\mathrm{H}_{2} \mathrm{SO}_{4}\right)$ : Acetonitrile (Fisher, A/0627/17), 85:15 (v/v), was pumped at a flow rate of 1.5 $\mathrm{ml} / \mathrm{min}$. The analysts were detected at $360 \mathrm{~nm}$. The injected volume was $25 \mu \mathrm{l}$ and chromatography was performed at $24^{\circ} \mathrm{C}$.

\section{STANDARD CURVE}

The stock standard solution of each TCS compound was primed by dissolving $10 \mathrm{mg}$ of each oxytetracycline (OTC), tetracycline (TTC), chlortetracycline (CTC), and doxycycline (DOC) in $10 \mathrm{~mL}$ of methanol to obtain a final concentration of $1 \mathrm{mg} / \mathrm{ml}^{-1}$. Stock standard solutions were put in amber glass to prevent photo-degradation and stored at $20^{\circ} \mathrm{C}$ and were stable for at least 4 weeks. Stock solutions were diluted with methanol to give a series of working standard solutions $(25,50,100,250,500$, and $1000 \mu \mathrm{g})$ that were prepared weekly. The best fit of data was determined using linear regression from Microsoft Excel that uses the following equation:

$$
Y=m x+b
$$

Where;

$\mathrm{Y}=$ Peak area, $\mathrm{x}=$ TCS concentration $\left(\mu \mathrm{kg}^{-1}\right) ; \mathrm{m}=$ Slope of curve, and $b=$ Intercept of $y$.

\section{STATISTICAL ANALYSIS}

All values are presented as means \pm standard Error. The antibiotic residues were expressed as $\mu \mathrm{g} / \mathrm{kg}$. The statistical analysis for this study was performed using SPSS 16 (2007). Data were subjected to a one-way analysis of variance (ANOVA). Any significant differences $(\mathrm{P}<0.05)$ were analyzed by the multiple comparison procedures of LSD (least significant difference), using a level of significance of alpha $=0.05$.

\section{RESULTS AND DISCUSSION}

Tetracyclines are one of the most necessary and effective poultry drugs of intensive chicken production in the World. Results in Table 1 declare that the incidence of tetracycline was $260(87 \%)$ in all examined broiler meat. The high residual levels of tetracycline may be attributed to the intensive use of tetracycline in chicken farms for diseases control, as well as growth promoters. Broiler stockholders use it as cheap and effective antibiotics for the control of infectious diseases and as feed additives at sub-therapeutic levels as growth-promoting agents (Hussein and Khalil, 2013). Tetracyclines are broad-spectrum antibiotics that are widely used against infectious pathogens which are commonly used in the cure of chicken bacterial diseases (Menkem et al., 2018).

Table 1: Qualitative results for tetracycline concentrations in broilers meat samples $(n=300)$.

\begin{tabular}{lllll} 
Broilers & \multicolumn{2}{c}{ Positive samples } & \multicolumn{2}{c}{ Negative samples } \\
samples & No. & $\%$ & No. & $\%$ \\
TCS & 260 & $87 \%$ & 40 & $13 \%$
\end{tabular}

The existence of antibiotic traces in human food can pretense risks to human health. Among these risks are antibiotics sensitivity, allergic reactions, imbalance of natural microflora, bacterial resistance to antibiotics, and losses in the food industry (Cunha, 2001). The results obtained by Jahantigh et al. (2020) emphasize the want for cautious use of tetracycline in broilers farming to minimize the occurrence of tetracycline-resistant pathogens. They added that antibiotics from different members will need to be used to limit antimicrobial resistance and extra correctly deal with infectious diseases of chicken.

The number of positive broilers samples for OTC, TTC, CTC, and DOC in Table 2 were 90, 34, 16, and 120 samples, respectively. The mean concentration values of OTC, TTC, CTC, and DOC in chicken samples were $160.26,89.19,98.75$, and $175.64 \mu \mathrm{g} / \mathrm{Kg}$, respectively. The concentration levels for OTC were 75.31 to 210.63 , TTC 70.60 to 115.30 , CTC 89.54 to 120.20 , and DOC 103.14 to $210.98 \mu \mathrm{g} / \mathrm{Kg}$. Several studies had been screened tetracycline residues in chicken meat with recorded different values (Shareef et al., 2009; Yu et al., 2011; Hakem et al., 2013; Karmi, 2014). Residues of TCS in broilers meat have been determined in various investigations globally and are considered one of the probable causes of antimicrobial resistance in human pathogens (Muaz et al., 2018). This result confirmed the widespread misuses of TCS in a chicken farm and the lack of application of recommended withdrawal times (Patrabansh et al., 2020). 
Table 2: Quantitative average values of tetracycline concentrations $(\mu \mathrm{g} / \mathrm{Kg})$ in the broilers meat $(\mathrm{n}=260)$.

$\begin{array}{llllll}\text { TCS } & \text { Positive No. } & \text { Means } & \text { Range } & { }^{*} \pm \text { SE } & \text { MRL } \boldsymbol{\mu g} / \mathbf{k g} \text { in chicken meat }(\mathbf{E O S}, \mathbf{2 0 1 0}) \\ \text { OTC } & 90 & 160.26^{\mathrm{a}} & 75.31-210.63 & 36.21 & 100 \\ \text { TTC } & 34 & 89.19^{\mathrm{b}} & 70.60-115.30 & 20.51 & 100 \\ \text { CTC } & 16 & 98.75^{\mathrm{c}} & 89.54-120.20 & 33.97 & 100 \\ \text { DOC } & 120 & 175.64^{\mathrm{a}} & 103.14-210.98 & 59.87 & 100 \\ \text { Total samples No. } & 260 & - & - & - & -\end{array}$

${ }^{*} \mathrm{SE}$ means Standard Error; Means in the column followed by the same letters are not significantly different $(\mathrm{P}<0.05)$.

Among TCS, oxytetracycline (OTC) and doxycycline (DOC) are the most extensively used in chicken farms. The results revealed that there were significantly different $(\mathrm{P}<0.05)$ in the mean concentration values of OTC, DOC, and TTC, CTC. It is mainly owing to their low cost, availability, long-acting, and broad-spectrum antimicrobial activity. DOC is often used to treat avian infectious diseases such as colibacillosis, salmonellosis, staphylococcosis, mycoplasmosis, and chlamydiosis (Akbar et al., 2009).

The Egyptian Organization for Standardization and Quality Control (EOS, 2010, No. 7136) is set a standard limit for tetracycline levels in poultry which must not exceed $100 \mu \mathrm{g} / \mathrm{Kg}$. In the same issue, the international regulations as Food and Agricultural Organization, World Health Organization (FAO/WHO), and the European Union have recommended a maximum residue limit (MRL) of $100 \mu \mathrm{g} / \mathrm{kg}$ for tetracycline, oxytetracycline and/ or chlortetracycline (singly or in combination) in food (Applegren et al., 1999; Codex Alimentarius, 2013).

Based on the local and international regulations, the obtained results in Table 3 reveal that out of 260 positive samples for tetracycline concentration, 170 (65.4\%) were unfit for the MRL, and 90 (34.6\%) chicken samples were agreed with the MRL. The number and percentages of OTC, TTC, CTC, and DOC positive chicken samples that fit the MRL were $63(24.2 \%), 21(8.1 \%), 6$ (2.3\%), and $0(0 \%)$, respectively. The number and percentages of OTC, TTC, CTC, and DOC positive chicken samples unfit the MRL were 27 (10.4\%), 13 (5\%), 10 (3.8\%), and $120(46.2 \%)$, respectively.

Using tetracycline in broilers may cause deposition of their traces in the meat and eggs. Using unlabeled drugs, wrong applications or kinds of drugs are some of the reasons for residue occurrence. According to a study conducted on 33 chickens, results confirm that 29 (69.7\%) broilers have antibiotic residue over MRL (Al-Ghamdi et al., 2000). Nowadays, one of the most important adverse effects of antibiotic residues of chicken meat is developed antibiotic-resistant pathogens. Antibiotic resistance has been described as one of the world's most pressing health problems globally. Many human pathogens are becoming resistant to the most commonly prescribed treatment. Antibiotic resistance has been identified as one of the three greatest threats to human health by WHO (Lemus et al., 2008). Resistant pathogens are transferred to food consumers through the food lead to adverse health consequences (Ventola, 2015).

Table 3: Average concentration of tetracycline $(\mu \mathrm{g} / \mathrm{Kg})$ in the broilers meat in compared to Egyptian Legislations $(n=260)$.

\begin{tabular}{|c|c|c|c|c|c|}
\hline \multirow[b]{3}{*}{ TCS } & \multirow{3}{*}{$\begin{array}{l}\text { Total positive } \\
\text { samples } \\
\text { No. }\end{array}$} & \multicolumn{4}{|c|}{ Chicken samples } \\
\hline & & \multicolumn{2}{|c|}{ Fit MRL } & \multicolumn{2}{|c|}{ Unfit MRL } \\
\hline & & No. & $\%$ & No. & $\%$ \\
\hline OTC & 90 & 63 & 24.2 & 27 & 10.4 \\
\hline TTC & 34 & 21 & 8.1 & 13 & 5 \\
\hline СTC & 16 & 6 & 2.3 & 10 & 3.8 \\
\hline DOC & 120 & 0 & 0 & 120 & 46.2 \\
\hline Total & 260 & 90 & 34.6 & 170 & 65.4 \\
\hline
\end{tabular}

*EOS (2010) Maximum Permissible Limits (MRL) is $100 \mu \mathrm{g} /$ $\mathrm{kg}$ in chicken meat.

TCS residues are unstable drugs that will be degraded during cooking, rendering broilers meat safe for human consumption according to the permissible limit cited in this issue. The mean concentration values of OTC, TTC, CTC, and DOC in Table 4 in control positive samples were $142.34,76.15,84.12$, and $163.27 \mu \mathrm{g} / \mathrm{Kg}$, respectively.

Several studies have been done to study the effect of cooking methods on antibiotic residues in chicken meat (Javadi, 2011; Hussein and Khalil, 2013; Kanbur et al., 2014). The study results confirmed that some cooking trials cannot guarantee the complete removal of the TCS residues and can only reduce the concentrations of these drug residues to a safer level. The most conmen ways of cooking preferred by most Egyptians are oven cooking, boiling, sauteing on a pan, frying in deep and grill.

In the current study, after the samples were simmered, the mean concentration values of OTC, TTC, CTC, and DOC were significantly reduced $(\mathrm{P}<0.05)$ to $18.71,8.70,10.45$, and $23.15 \mu \mathrm{g} / \mathrm{Kg}$, respectively, with a reduction parentage of $87 \%, 89 \%, 88 \%$, and $86 \%$ respectively. All samples cooked by simmering were fit with the national and international legislation and considered safe for consumers. 
Table 4: Effect of simmering and frying on tetracycline concentrations $(\mu \mathrm{g} / \mathrm{Kg})$ in the broilers meat.

$\begin{array}{lllllllll}\text { TCS } & \begin{array}{l}\text { Samples } \\ \text { no. }\end{array} & \text { Control positives } & \begin{array}{l}\text { Chicken } \\ \text { simmering }\end{array} & \begin{array}{l}<\mathbf{M R L} \mathbf{~ 1 0 0} \\ \boldsymbol{\mu g} / \mathbf{k g}\end{array} & { }^{*} \mathbf{R} \% & \text { Chicken frying } & \begin{array}{l}<\mathbf{M R L} \mathbf{1 0 0} \\ \boldsymbol{\mu g} / \mathbf{k g}\end{array} & \mathbf{R} \% \\ \text { OTC } & 10 & 142.34^{* *} \pm 30.45 & 18.71 \pm 2.64 & 10 & 87 & 70.11 \pm 16.81 & 6 & 51 \\ \text { TTC } & 10 & 76.15 \pm 15.21 & 8.70 \pm 1 . .05 & 10 & 89 & 33.74 \pm 3.91 & 10 & 56 \\ \text { CTC } & 10 & 84.12 \pm 12.67 & 10.45 \pm 1.94 & 10 & 88 & 30.47 \pm 4.62 & 10 & 65 \\ \text { DOC } & 10 & 163.27 \pm 40.28 & 23.15 \pm 2.67 & 10 & 86 & 78.47 \pm 11.60 & 4 & 52\end{array}$

*R \% means reduction percents; ${ }^{*}{ }^{*}{ }^{*} \mathrm{SE}$ means standard error; Means in the row followed by the same letters are not significantly different $(\mathrm{P}<0.05)$.

After the samples were fried, the means concentration values of OTC, TTC, CTC, and DOC were significantly reduced $(\mathrm{P}<0.05)$ to $70.11,33.74,30.47$, and $78.47 \mu \mathrm{g} / \mathrm{Kg}$, respectively, with reduction parentage of $51 \%, 56 \%, 65 \%$, and $52 \%$, respectively. All samples positive to TTC and CTC and cooked by frying were fit with the national and international legislation and considered safe for consumers meanwhile, out of 10 samples positive to OTC and DOC, 6 and 4 chicken samples were fit the MRL.

Long time cooking at low temperature like the simmering method is the ideal method for cooking to effectively reduce antibiotic residues in chicken meat before consumption (Fathy et al., 2015). Sufficient cooking temperature and time can have a significant effect on the losses of TC residues and provide an added margin of safety for humans (Abou-Raya et al., 2013). A recent study was conducted by Vivienne et al. (2018) confirmed that boiling is more effective in decreasing the concentration of TCS in chicken meat, while roasting was more effective in decreasing the concentration of broiler bird liver samples.

\section{CONCLUSIONS AND RECOMMENDATIONS}

The results of the study emphasize that TCS resides still has problems in the broilers meat traded at Ismailia City, Egypt. Cooking by simmering is the best method to guarantee consumers safe of broilers meat. Veterinarians play a central role in ensuring the careful use of TCS in chicken production. Training chicken farmers to monitor withdrawal periods of TCS and choose the correct time for chicken slaughtering. Authority in concern must be strong applying the issued legislations to prevent the emergence of antibiotic resistance pathogens related to chicken production.

\section{NOVELTY STATEMENT}

The research paper resides uniquely the effects of cooking methods such as simmering and frying on tetracycline residues detected in broiler chicken meat and detected that simmering is the best method guarantee consumers almost safe of broiler chicken meat.

\section{AUTHOR'S CONTRIBUTION}

HMS participated in the analysis of the samples, and took a part in writing the manuscript. AMA designed the experimental design, supervised the in-vivo experiment, and took a part in rewriting the manuscript. HAA designed the experimental design, supervised the in-vivo experiment, and took a part in rewriting the manuscript. RHA participated in the analysis of the samples, and took a part in rewriting the manuscript. ASM participated in the analysis of the samples, and took a part in writing the manuscript.

\section{CONFLICT OF INTEREST}

The authors have declared no conflict of interest.

\section{REFERENCES}

Abou-Raya S, Shalaby A, Salama N, Emam W, Mehaya M (2013). Effect of ordinary cooking procedures on tetracycline residues in chicken meat. J. Food Drug Anal., 21(1): 80-86.

Akbar H, Khan M, Khan A, Khan M, Shuaib M, Akbar S, Manzoor S, Irshad-ur-Rehman A, Ahmad S, Ali L, Khalid $R$, Idrees M (2009). Comparative efficacy of doxycycline and flumequine against experimentally induced colibacillosis in broiler chicks. J. Vet. Med. Anim. Health, 1(2): 17-22.

Al-Ghamdi MS, Al-Mustafa SH, El-Morsy F, Al-Faiky A, Haider I, Essa H (2000). Residues of tetracyline compounds in poultry products in the eastern provience of Saudi Arabia. Publ. Health,114: 300-304. https://doi.org/10.1016/S00333506(00)00350-4

Al-Nazawi MH, Homeida AM (2005). Residues of sulphadimidine and its metabolites N4-acetyl in camel milk. Pak. J. Biol. Sci., 8: 421-432.

Applegren L, Arnold D, Boisseau J, Boobis A, Ellis R, Livingston $R$ (1999). Evaluation of certain veterinary drug residues in food. $15^{\text {th }}$ Rep. Joint FAO/WHO Expert. Committ. Food Addit., 888: 1-95.

Chopra I, Roberts M (2001). Tetracycline antibiotics: Mode of action, applications, molecular biology, and epidemiology of bacterial resistance. Microbiol. Mol. Biol. Rev., 65(2): 232237. https://doi.org/10.1128/MMBR.65.2.232-260.2001

Codex Alimentarius Commission, FAO, WHO, (2013). Maximum residue limits for veterinary drugs in foods. Updated as at the $34^{\text {th }}$ session of the Codex Alimentarius Commission. 
Cunha BA (2001). Antibiotic side effects. Med. Clin. North Am., 85: 149-185. https://doi.org/10.1016/S00257125(05)70309-6

FAO (2017). Broiler poultry industry: investment challenges and opportunities. p. 14.

Egyptian Organization Standardization (EOS) (2010). Maximum level for certain contaminants in food stuffs. ES No. 7136/2010.

Fathy F, Ahmed AM, Moursi MK (2015). Effect of cooking methods on antibiotic residues in broiler chicken meat. $2^{\text {nd }}$ Conf. Food Saf. Suez Canal Univ. Fac. Vet. Med., I: 76-81.

Gowtham P, Muthukumar M, Eswara Rao B, Kalpana S, Keerthika V, Dani Nishant JA (2020). Impact of cooking methods of meat on antibiotic residues: Review. Pharm. Innov., 9(12): 303-309. https://doi.org/10.22271/tpi.2020. v9.i12e.5454

Hakem A, Titouche Y, Houali K, Yabrir B, Malki O, Chenouf N, Yahiaoui S, Labiad M, Ghenim H, Kechih-Bounar S, Chirila F, Lapusan A, Fit NI (2013). Screening of antibiotics residues in poultry meat by microbiological methods. Vet. Med., 70: 77-82.

Henry SG, Darwish SM, Saleh AS, Khalifa AH (2019). Carcass characteristics and nutritional composition of some edible chicken products. Egypt. J. Food Sci., 47(1): 81-90.

Hussein MA, Khalil S (2013). Screening of some antibiotics and anabolic steroids residues in broiler fillet marketed in elsharkia governorate. Life Sci. J., 10: 2111-2118.

Hussein M, Ahmed M, Morshedy A (2016). Effect of cooking methods on some antibiotic residues in chicken meat. Japanese J. Vet. Res., 64(2): 225-231.

Jahantigh M, Samadi K, Dizaji R, Salari S (2020). Antimicrobial resistance and prevalence of tetracycline resistance genes in Escherichia coli isolated from lesions of colibacillosis in broiler chickens in Sistan. Iran. Vet. Res., 16: 267-274. https://doi.org/10.1186/s12917-020-02488-z

Javadi A (2011). Effect of roasting, boiling and microwaving cooking method on doxycycline residues in edible tissues of poultry by microbial method. Afr. J. Pharm., 5(8): 10341037. https://doi.org/10.5897/AJMR11.713

Kanbur M, Liman BC, Eraslan G, Baydan E, Dïnç E, Karabacak $M$ (2014). Effects of various cooking and freezing processes on the residues of sulfachlorpyridazine-trimethoprim combination in broiler tissues. Kafkas Üniv. Vet. Fak. Dergisi, 20: 487-492. https://doi.org/10.9775/kvfd.2013.10220

Karmi M (2014). Detection and presumptive identification of antibiotic residues in poultry meat by using FPT. Glob. J. Pharm., 8: 160-165.

Kulandaivelu K, Rajini R, Sarathchandra G, Ezhilvalavan S (2018). Evaluating drug withdrawal time of in-fed antibiotic Chlortetracycline in layer chicken. Int. J. Adv. Biotechnol. Res., 8(1): 49-52.

Lemus J, Blanco G, Grande J, Arroyo B, Garcia-Montijano M, Martınez (2008). Antibiotics threaten wildlife: Circulating quinolone residues and disease in avian scavengers. Plussone, 1: 1-6. https://doi.org/10.1371/journal.pone.0001444

LoWY,FriedmanJM(2002).Teratogenicityof recentlyintroduced medications in human pregnancy. Obstet. Gynecol., 100(3): 465-473. https://doi.org/10.1097/00006250-20020900000012

Menkem E, Ngangom L, Tamunjoh S, Boyom F (2018). Antibiotic residues in food animals: Public health concern. Acta Ecol. Sin., 621: 5. https://doi.org/10.1016/j.chnaes.2018.10.004

Muaz K, Riaz M, Akhtar S, Park S, Iismil A (2018). Antibiotic residues in chicken meat: Global prevalence, threats, and decontamination strategies: A review. J. Food Prot., 81(4): 619-627. https://doi.org/10.4315/0362-028X.JFP-17-086

Mund M, Khan U, Tahir U, Mustafa B, Fayyaz A (2017). Antimicrobial drug residues in poultry products and implications on public health: A review. Int. J. Food Prop., 20(7): 1433-1446. https://doi.org/10.1080/10942912.2016 .1212874

Nguyen F, Starosta A, Arenz S, Sohmen D, Dönhöfer A and Wilson D (2013). Tetracycline antibiotics and resistance mechanisms. J. Biol. Chem., 395(5):559-575.

Nikolaidou KI, Samanidou VF, Papadoyannis IN (2008). Development and validation of an HPLC method for the determination of seven tetracycline antibiotics residues in chicken muscle and egg yolk according to 2002/657/EC. J. Liquid Chromat. Relat. Technol., 31(14): 2141-2158. https://doi.org/10.1080/10826070802225445

Nisha AR (2008). Antibiotic residues a global health hazard. Vet. World, 1(12): 375-377. https://doi.org/10.5455/ vetworld.2008.375-377

Patrabansh S, Parajuli N and Jha, V (2020). Rapid Detection of Tetracycline Residues in Chicken. Int. J. Appl. Sci. Biotechnol. 8(1): 14-20.

Prescott LM, Harley JP, Klein DA (2002). Microbiology (5 $5^{\text {th }}$ Ed.). https://trove.nla.gov.au/version/35077377, Retrieved April 15, 2019.

Rusu A, Buta E (2021). The development of third-generation tetracycline antibiotics and new perspectives. Pharmaceutics, 13: 2085-2115. https://doi.org/10.3390/pharmaceutics13122085

Senyuva H, Ozden T, Sarica D (2000). High-Performance Liquid Chromatographic Determination of Oxytetracycline Residue in Cured Meat Products. Turk J Chem., 24: 395 400.

Shareef M, Jamel ZT, Yonis KM (2009). Detection of antibiotic residues in stored poultry products. Iraqi J. Vet. Sci., 23: 4548.

Sivagami K, Vignesh VJ, Srinivasan R, Divyapriya G, Nambi IM (2020). Antibiotic usage, residues and resistance genes from food animals to human and environment: an Indian scenario. J. Environ. Chem. Eng., 8:102221.

SPSS 16 (2007). Statistical package for social science ver. 16 for Windows. SPSS Inc., Chicago, IL.

Tariq S, Rizvi S, Anwar U (2018). Tetracycline: Classification, structure activity relationship and mechanism of action as a theranostic agent for infectious lesions. A mini review. Biomed. J. Sci. Tech. Res., 5(4): 5787-5796.

Tetracycline Rapid Test Kit (2010). Buy tetracycline, food safety testing kit, tetracycline residues in meat product on Alibaba. www.alibaba.com/productdetail/ Tetracycline-Rapid-TestKit-Tissue.

Ventola CL (2015). The antibiotic resistance crisis, part 1: Causes and Threats. Pharm. Ther., 40(4): 277-283.

Yu H, Tao Y, Chen D, Wang Y, Yuan Z (2011). Development of an HPLC-UV method for the simultaneous determination of tetracyclines in muscle and liver of porcine, chicken and bovine with accelerated solvent extraction. Food Chem., 124: 1131-1138. https://doi.org/10.1016/j. foodchem.2010.07.024

Vivienne E, Josephine O and Anaelom N (2018). Effect of temperature (cooking and freezing) on the concentration of oxytetracycline residue in experimentally induced birds. Vet. World, 11(2): 167-171. 